\title{
Factors Affecting Exclusive Breast Feeding of Infants in Port Fouad City
}

\author{
Samar A. Elalfy ${ }^{1^{*}}$, Wesam A. Elsayed ${ }^{2}$, Ahmed G. Abdelrhman', and \\ Nahed A. Eldahshan'
}

${ }^{1}$ Department of Family Medicine, Faculty of Medicine, Suez Canal University and ${ }^{2}$ Department of Family Medicine, Ministry of Health, Egypt

\begin{abstract}
Background: Exclusive breastfeeding during the early months of life reduces infant morbidity and mortality, World Health Organization (WHO) defines exclusive breastfeeding as, feeding an infant only with breast milk, excluding solids or any other fluids (including infant formulas) except medicines, vitamins, and minerals, WHO recommended infants to be exclusively breastfed during first 6 months of life Aim: to improve maternal and child health by encouraging exclusive breastfeeding till six months. Subjects and Methods: The present study was designed as a descriptive cross-sectional study that included 670 mothers of infants who came to primary health care centers (El Herafien and El Amal) for vaccination. to determine the Factors Affecting Exclusive Breast Feeding of Infant till six months. Results: This study showed that $10.3 \%$ of mothers practice exclusive breastfeeding for 6 months, 9.7\% practice artificial feeding, and most of the mothers $80 \%$ practice mixed feeding.33.9\% initiated BF early within the first hour and two-thirds initiated it after the first hour of delivery and there was a strong relationship between exclusive breastfeeding and early initiation of breastfeeding $(\mathrm{OR}=5.8)$. Conclusion: From the previous results, Egypt is one of the developing countries in which we need to support correct feeding practices. Exclusive breastfeeding is a safe, economical, and emotionally satisfying means of feeding babies.
\end{abstract}

Keywords: feeding of infants, maternal health, child health.

\section{Introduction}

Infant nutrition is an important determinant of future health ${ }^{(1)}$. The long-term benefits of breastfeeding in enhancing maternal and infant health for several years ${ }^{(2)}$. Compared to exclusively breastfed infants, formula-fed infants are not only deprived of the benefits of breast milk but also more likely of respiratory infection, otitis media, and sudden infant death syndrome ${ }^{(1)}$. Moreover, formula-fed infants are more likely to rapid weight gain in their first year of life, which increases their risk to develop childhood obesity with its subsequent complications $^{(3)}$. Despite an increasing body of knowledge and world health organization (WHO) recommendations on breastfeeding, the global picture falls short of these standards, as only $35 \%$ of infants worldwide are exclusively breastfed. In Egypt, breastfeeding practices are not always optimal. Exclusive breastfeeding (EBF) among infants under two months of age constitutes $71 \%{ }^{(4)}$. Recent studies on cesarean childbirths in Egypt unveiled that the country ranked third in the world, after Brazil and the Dominican Republic, and 
first in the Middle East, after experiencing an alarming increase of 52 percent in cesarean childbirths ${ }^{(5)}$. Despite Caesarean Section (C.S.) being four-times more dangerous than regular deliveries, the study, which was released by United Nation Population Fund (UNPF), revealed an increase in the number of cesarean deliveries since 2005 in Egypt, with the most significant increase taking place between 2008 and 2014, remarkably doubling from 26.7 percent to 51.8 percent. Also, early initiation of breastfeeding is important for both the mother and the child. Early suckling stimulates the release of hormones that help in the production of milk. It also stimulates the contraction of the uterus after childbirth. WHO, United Nation International Children's Emergency Fund (UNICEF) says that rates of early initiation of breastfeeding decreased from $40 \%$ to $27 \%$ due to an increased rate of C.S. ${ }^{(6)}$. Many studies have highlighted the negative effects of formula supplementation on the breastfeeding (BF) relationship, few have highlighted the reasons that women choose to formula feed their infants. So, it is important to explore the mother's attitudes towards breastfeeding and to identify the infant characteristics to evaluate which interventions are needed to promote breastfeeding $(B F)^{(7)}$. As one of the essential roles of family physicians is to promote, protect, support breastfeeding (BF) as the ideal method of infant feeding and encourage mothers to initiate BF as early as possible, and continue lactation till 6 months, and be knowledgeable about the basics of lactation, physiological, psychological benefits of breastfeeding (BF) to her and her baby. So, when compared with internationally recommended infant feeding practices, Egyptian mothers have been moving steadily in the wrong direction, although the promotion of exclusive breastfeeding is the single most cost-effective intervention to reduce infant mortality in developing countries ${ }^{(8)}$. It seems clear that the decline in exclusive breastfeeding has been due to the combination of inadequate support for breastfeeding and the subsidization of infant formula by the government and it is not clear why Egypt's physicians would take this position. There is no compelling medical reason for the large-scale sustained subsidy of infant formula by any government. So, we are conducting this study to bridge the gap between current breastfeeding practices and the recommendation of the $\mathrm{WHO}^{(9)}$. Furthermore, a detailed understanding of the regional prevalence along with the determinants of exclusive breastfeeding (EBF) is essential for decision-makers to provide locally relevant policies and resources, and for public health administrators to design targeted interventions to improve BF. The current work aimed to improve maternal and child health by encouraging exclusive breastfeeding till six months.

\section{Subjects and Methods}

This descriptive cross-sectional study was carried out in Port Fouad primary health care centers related to the Ministry of Health (ElAmal and El Herafien). Port Fouad city is an Egyptian city that follows Port Said governorate. It was founded in 1920 represents the Asian part of this AfroAsian government, as it is located on the coast of the Mediterranean Sea in the northwest corner of the Sinai Peninsula. It was planned to take a sample sufficient to demonstrate a $13 \%$ prevalence of exclusive breastfeeding in the first 6 months with a $95 \%$ confidence interval. the sample size was equal to 670. Data were collected from mothers 3 days per week, days of immunization from 9 AM to 12 PM, 2 days for 
6-month immunization and 1 day for 9month immunization from November 2019 to February 2020, the first 3month was in El Amal primary health care where present the bulk of immunization and collect about 447 of the sample there and last month in El Herafine primary health care and collect about 223 of the sample there.

\section{Study population}

A simple randomly selected sample of Mothers who have infants aged 6 months up to 9 months old attending El Amal and El Herafine Port Fouad health care centers for vaccination. All the mothers of full-term Infants aged 6-9 months coming to wellbaby clinics and immunization rooms were included. Mothers with multiple babies, or with absolute contraindication for breastfeeding (cancer breast, HIV, etc.) or with ill infants (cleft lip, cleft palate, PKU, galactosemia, pathological jaundice, etc.) were excluded from the study

\section{Methods}

All mothers in the study were subjected to i) Personal interview, using a simple concise, and informative questionnaire to collect the following data.

1-Socio demographic data of the mothers and their families (i.e., mother and father age, education, employment status, and Socioeconomic status by using the El Gilany and El Wehady scale ${ }^{(10)}$.

2-Health service that included the number of antenatal clinic visits, the place, and mode of delivery

3-Child factors that included infant gender, age, weight, length, Birth order, and preceding birth interval.

4-Assessment types of baby feeding (breastfeeding, artificial or mixed),

5-IF artificial, age of the baby when stop $\mathrm{BF}$ ?

6-Causes that led to stopping breastfeeding.; Breastfeeding is not sufficient for the infant, wanting to start weaning, the opinion of the infant's father, Use of hormonal contraceptives, encouraged by the doctor, Employment/study, Sick/unable to breastfeed. The belief that the formula is equal to or better than breast milk, Mother nipple pain/cracks, Mother medications, Previous negative breastfeeding experience, or The desire to diet to lose weight

The second part was observational for How to breastfeed

Assessment of good position (baby body should be straight and slightly extended, close to the mother's body, Whole body supported and Baby facing toward the mother's breast

Assessment of Correct of attachment: More areola is visible above the baby's top lip, The baby's mouth is wide open, the baby's lower lip is turned outwards, the baby's chin is touching or almost touching the breast

Assessment of effective suckling: Slow sucks, Deep suckling, and sometimes pausing

\section{Results}

The study was designed as a descriptive cross-sectional study that included 670 mothers of infants aged 6 up to 9 months was attended port Fouad health care centers (El Amal and El Herafien) for immunization. the socio-demographic data of 670 mothers, shows that the mean age (SD) of the participating mothers was 28.86 (3.96), $52.4 \%$ of them were $<30$ years, and $47.6 \% \geq 30$ years. $68.1 \%$ of mothers were workers versus $31.9 \%$ housewives. Only $4.9 \%$ of mothers were illiterate, $27 \%$ were secondary educated and most mothers were university educated. $16.4 \%$ of mothers had low SES, $41.9 \%$ middle SES and another $41.9 \%$ had high SES (by using El Gilany and El Wehady scale) Table (1). Most of the mothers (92.1\%) received antenatal care. 
$33.4 \%$ of them received more than 4 visits and $75.1 \%$ of them received ANC in private clinics $69.1 \%$ of mothers delivered in private hospitals while $30.9 \%$ got birth at governmental hospitals. Neonatal characteristics among the participating mothers; show that $52.5 \%$ of neonates were males versus
47.5\% females, mean (SD) gestational age was 38.31 (1.01), their weight at delivery was $3276.7 \mathrm{~g}$ (298), their length $50.04 \mathrm{~cm}$ (1.39), mean weight at the time of study $7713.4 \mathrm{~g}$ (491) while mean length $68.27 \mathrm{~cm}$ (1.88). $29.9 \%$ of neonates had physiological jaundice, $78.8 \%$ their birth order $\leq 2$.

\begin{tabular}{|l|c|}
\hline \multicolumn{2}{|c|}{ Table 1: Socio-demographic data of the studied group } \\
\hline Socio-demographic data & $\begin{array}{c}\text { The studied group } \\
(\mathrm{n}=670)\end{array}$ \\
\hline Mothers' age/ years & \\
Mean \pm SD & $28.86 \pm 3.69$ \\
$<30$ y & $351(52.4 \%)$ \\
$\geq 30$ y & $319(47.6 \%)$ \\
\hline Mother's Occupation & \\
Working Mothers & $456(68.1 \%)$ \\
Housewife & $214(31.9 \%)$ \\
\hline Mother's Education & \\
Illiterate & $33(4.9 \%)$ \\
Secondary educated & $181(27 \%)$ \\
University educated & $456(68.1 \%)$ \\
\hline Father's Occupation & \\
Working & $631(94.2 \%)$ \\
Non-working & $39(5.8 \%)$ \\
\hline Father's Education & $33(4.9 \%)$ \\
Illiterate & $234(34.9 \%)$ \\
Secondary educated & $403(60.2 \%)$ \\
University educated & \\
\hline SES & $110(16.4 \%)$ \\
Low & $281(41.9 \%)$ \\
Middle & $279(41.7 \%)$ \\
High &
\end{tabular}

while $21.2 \%$ their order $>2$ Table (2). About one-third $33.9 \%$ initiated BF early within the first hour and two-thirds initiated it after the first hour of delivery. Among 601 mothers who stopped exclusive BF, 6.2\% were never breastfed infants. $51.8 \%$ stopped at 3rd month, $31.4 \%$ at 4 th month, and $10.6 \%$ after 5 th month. $53.3 \%$ of mothers use herbal in the first 3 days. Table (3). The most comments barriers for exclusive $\mathrm{BF}$ and causes of cessation of exclusive BF; $72.4 \%$ of mothers stopped EBF due to family and home responsibilities, $72.4 \%$ felt constrained, $58.9 \%$ said milk is not enough,
$58.9 \%$ were convinced that breastfeeding is not sufficient for infants in general, $40.6 \%$ wanted to start weaning, $39.1 \%$ stopped under the pressure of infant's father, $36.4 \%$ wanted to use hormonal contraception for birth spacing, 31.1\% due to doctors opinion, $31.1 \%$ mothers working or studying, $23 \%$ sick mothers or unable to breastfeed, 23\% the belief that the formula is equal to or better than breast milk, $23 \%$ nipple pain or cracks, $8.3 \%$ because of mothers taking medications, $4.7 \%$ due to previous negative breastfeeding experience, and $4.7 \%$ of mothers stopped EBF 
due to the desire to diet to lose weight Figure (1). The correct baby position criteria show that $12.1 \%$ of breastfeeding mothers had poor grades, $22.9 \%$ average grades, and $65 \%$ showed good correct baby position.

\begin{tabular}{|l|c|}
\hline \multicolumn{2}{|c|}{$\begin{array}{c}\text { Table (2): Neonatal demographic and clinical characteristics } \\
\text { among the studied group. }\end{array}$} \\
\hline Neonatal characteristics & $\begin{array}{c}\text { The studied group } \\
(\mathrm{n}=670)\end{array}$ \\
\hline $\begin{array}{l}\text { Gender } \\
\text { Male } \\
\text { Female }\end{array}$ & $352(52.5 \%)$ \\
\hline Gestational age* & $318(47.5 \%)$ \\
\hline Weight at delivery ${ }^{*}$ & $38.31 \pm 1.01$ \\
\hline Length at delivery & $3276.71 \pm 298.5$ \\
\hline Present weight & $50.04 \pm 1.39$ \\
\hline Present length & $7713.4 \pm 491.9$ \\
\hline Jaundice (physiological) & $68.27 \pm 1.88$ \\
\hline Order among siblings & $200(29.9 \%)$ \\
$\leq 2$ & \\
$>2$ & $528(78.8 \%)$ \\
\hline$*=$ Mean \pm SD & $142(21.2 \%)$ \\
\hline
\end{tabular}

The correct attachment criteria show $12.1 \%$ of breastfeeding mothers had poor grades, $22.9 \%$ average grade and $65 \%$ showed good correct attachment, the correctness of effective suckling shows that $41.9 \%$ of breastfeeding mothers their babies had poor grades and $58.1 \%$ showed good correctness of effective suckling. A statistically significant relation was found between exclusive BF and the age of mothers. $14.5 \%$ of mothers aged less than $30 \mathrm{y}$ were exclusive breastfeeders compared to $5.6 \%$ among mothers aged more than or equal to 30 y $(O R=2.8)$ Table (4).

\begin{tabular}{|l|c|}
\hline \multicolumn{2}{|c|}{ Table (3): Type of feeding, among the studied mothers } \\
\hline Type of feeding & $\begin{array}{c}\text { The studied group } \\
(\mathrm{n}=670)\end{array}$ \\
\hline Type of feeding & $65(9.7 \%)$ \\
Artificial & $536(80 \%)$ \\
Mixed & $69(10.3 \%)$ \\
Exclusive & \\
\hline When starting after delivery & $227(33.9 \%)$ \\
Early within the first h & $443(66.1 \%)$ \\
After $1^{\text {st }}$ h of delivery & No=601 \\
\hline When stopping exclusive B.F & $37(6.2)$ \\
No breastfeeding & $311(51.8 \%)$ \\
At 3m & $189(31.4 \%)$ \\
At 4m & $64(10.6 \%)$ \\
At 5m & $357(53.3 \%)$ \\
\hline Using herbal in first 3 days & \\
\hline
\end{tabular}


There was a statistically significant relationship between exclusive BF and frequency of ANC visits, mothers receiving $>4$ visits of ANC practicing more EBF representing $16 \%$ compared to $8.8 \%$ in mothers receiving <4 ANC visits (OR=1.9). Early initiation of $B F$ associated with exclusive $B F$ represents $21.6 \%$ in mothers who started $B F$ within the 1st hour compared to only $4.5 \%$ in the late initiation group ( $\mathrm{OR}=5.8)$.

\begin{tabular}{|c|c|c|c|c|}
\hline Socio-demographic data & Total & $\begin{array}{c}\text { Exclusive } \\
\text { breastfeeding } \\
(\mathrm{n}=69)\end{array}$ & $\begin{array}{c}\chi^{2} \\
\text { (p-value) }\end{array}$ & $\begin{array}{c}\text { OR } \\
(95 \% \mathrm{Cl})\end{array}$ \\
\hline $\begin{array}{c}\text { Mothers age } \\
\quad<30 \mathrm{y} \\
\quad \geq 30 \mathrm{y}(\mathrm{r}) \\
\end{array}$ & $\begin{array}{l}351 \\
319 \\
\end{array}$ & $\begin{array}{l}51(14.5 \%) \\
18(5.6 \%)\end{array}$ & $\begin{array}{c}14.28 \\
\left(\leq 0.001^{*}\right)\end{array}$ & $\begin{array}{c}1 \\
2.8(1.6-4.9) \\
\end{array}$ \\
\hline $\begin{array}{l}\text { Mother's Occupation } \\
\text { Working M (r) } \\
\text { Housewife }\end{array}$ & $\begin{array}{l}456 \\
214 \\
\end{array}$ & $\begin{array}{c}21(4.6 \%) \\
48(22.4 \%)\end{array}$ & $\begin{array}{c}50.09 \\
\left(\leq 0.001^{*}\right)\end{array}$ & $\begin{array}{c}1 \\
5.9(3.5-10.3)\end{array}$ \\
\hline $\begin{array}{l}\text { Mother's Education } \\
\text { Illiterate } \\
\text { Secondary (general \& } \\
\text { technical of } 3 \text { or } 5 \mathrm{Y} \\
\text { University graduate }(r) \\
\end{array}$ & $\begin{array}{l}33 \\
181 \\
456 \\
\end{array}$ & $\begin{array}{l}6(18.2 \%) \\
15(8.3 \%) \\
48(10.5 \%) \\
\end{array}$ & $\begin{array}{l}1.8(0.17) \\
0.73(0.39)\end{array}$ & $\begin{array}{c}1.9(0.7-4.8) \\
0.8(0.4-1.4) \\
1 \\
\end{array}$ \\
\hline $\begin{array}{l}\text { Father's Occupation } \\
\text { Working F } \\
\text { Not working }(r) \\
\end{array}$ & $\begin{array}{l}631 \\
39 \\
\end{array}$ & $\begin{array}{l}62(9.8 \%) \\
7(17.9 \%)\end{array}$ & $\begin{array}{c}2.62 \\
(0.105)\end{array}$ & $\begin{array}{c}1 \\
0.5(0.2-1.2)\end{array}$ \\
\hline $\begin{array}{l}\text { Father's Education } \\
\text { Illiterate } \\
\text { Secondary (general \& } \\
\text { technical of } 3 \text { or } 5 Y \\
\text { University graduate }(r)\end{array}$ & $\begin{array}{c}33 \\
234 \\
403\end{array}$ & $\begin{array}{l}7(21.2 \%) \\
21(9.0 \%) \\
41(10.2 \%)\end{array}$ & $\begin{array}{c}3.8(0.051) \\
0.24(0.62) \\
-\end{array}$ & $\begin{array}{c}2.4(0.9-5.8) \\
0.8(0.5-1.5) \\
1\end{array}$ \\
\hline
\end{tabular}

$\chi^{2:}$ Chi-square test, OR: Odds ratio, Cl: Confidence interval, ( $\left.r\right)$ : reference group.

On the other hand, no statistically significant relation was found between EBF and ANC or Place of birth. Factors associated with exclusive breastfeeding were early initiation of breastfeeding ( $O R=5.8$ ), vaginal mode of delivery $(O R=4.7)$, Governmental hospital as a source of ANC $(\mathrm{OR}=4.3)$, and order of sibling more than two $(\mathrm{OR}=2.4)$. After logistic regression analysis and adjusting confounding factors the following were independent predictors for exclusive breastfeeding; Mother's occupation (Housewife) (OR=43), vaginal delivery $(\mathrm{OR}=28.5)$, early initiation of $\mathrm{BF}(\mathrm{OR}=6.5)$, mothers aged less than 30 y $(O R=2.4)$ and frequency of ANC visits $>4(\mathrm{OR}=2.3)$ Table (5). A statistically significant relation was found between EBF and the grade of the correct baby position. $13.7 \%$ of good baby position was associated with exclusive $\mathrm{BF}$ compared to only $5.5 \%, 7.9 \%$ in poor and average correct baby position respectively. A statistically significant relation was found also between exclusive BF and grade of correct of attachment. $13.7 \%$ of good baby position was associated with exclusive BF compared to only $5.5 \%, 7.9 \%$ in poor and average correct baby position respectively. $A$ statistically significant relation was found between exclusive BF and grade of the corredness of effective suckling. $13.7 \%$ of good effective suckling was associated with exclusive BF compared to only $8.2 \%$ in the poor grading group. 


\begin{tabular}{|c|c|c|c|}
\hline \multicolumn{4}{|c|}{$\begin{array}{l}\text { Table 5: Logistic regression analysis of independent predictors of } \\
\text { Exclusive Breast Feeding }(n=69)\end{array}$} \\
\hline Independent predictor & $\mathrm{B}$ & $\mathrm{P}$ & AOR $(95 \% \mathrm{Cl})$ \\
\hline Mothers age $<30 \mathrm{y}$ & 0.877 & 0.016 & $2.4(1.2-4.9)$ \\
\hline Mother's Occupation (Housewife) & 3.770 & $\leq 0.001$ & $43(14-126)$ \\
\hline Frequency of ANC visits $>4$ & 0.861 & 0.015 & $2.3(1.1-4.7)$ \\
\hline Mode of delivery (VD) & 3.349 & $\leq 0.001$ & $28.5(9.9-81)$ \\
\hline Initiation of BF (Early) & 1.868 & $\leq 0.001$ & $6.5(3.3-12.7)$ \\
\hline $\begin{array}{l}\text { Constant } \\
\text { Model } \chi^{2} \\
\% \text { Correctly predicted }\end{array}$ & \multicolumn{3}{|c|}{$\begin{array}{c}-7.23 \\
175, p=\leq 0.001 \\
94.5 \%\end{array}$} \\
\hline
\end{tabular}

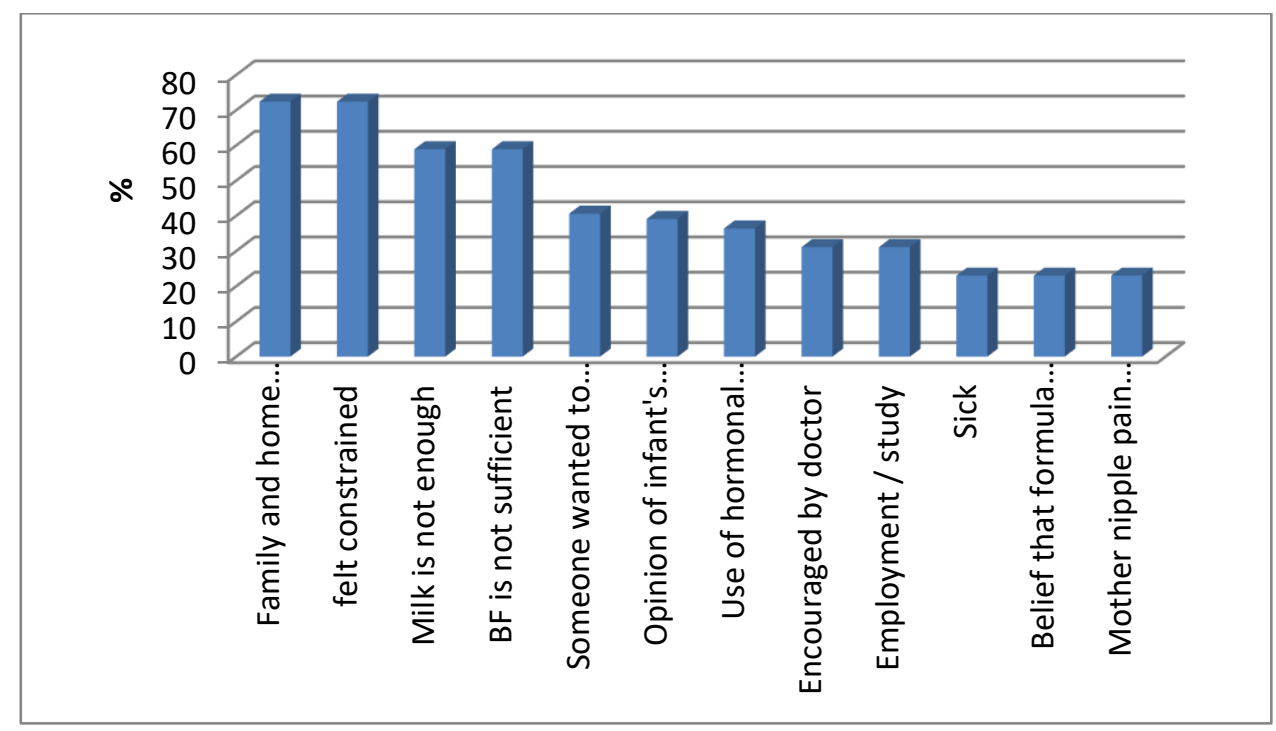

Figure 1: Causes of cessation of exclusive Breast Feeding

\section{Discussion}

Optimal breastfeeding practice decreases child death and contributes significantly to the long-term health of children. In 2016, a Lancet series estimated that 823,000 deaths of children under five years could be prevented every year through optimal breastfeeding practices ${ }^{(11)}$. Optimal breastfeeding practices reduce hospitalization among children from diarrhea, respiratory infections, and otitis media illnesses ${ }^{(12)}$. Although there was a universal awareness and high level of knowledge about exclusive breastfeeding, this study showed that $10.3 \%$ of mothers practice exclusive breast- feeding for 6 months, $9.7 \%$ practice artificial feeding, and most the mothers $80 \%$ practice mixed feeding. Globally, just 38\% of infants less than 6 months are exclusively breastfed ${ }^{(13,14)}$. In the current study, the prevalence of EBF was seen in $28.6 \%$, whereas $54.6 \%$ were mixed-fed, and only $16.8 \%$ of the infants were not breastfed. This finding was supported by El-Zanaty who found that only $40 \%$ of children under 6 months were EBF, 54\% received mixed feeding, and only $7 \%$ were not breastfed ${ }^{(16)}$. In the current study, $33.9 \%$ initiated BF early within the first hour and two-thirds initiated it after the first hour of delivery and there was a strong relationship between 
exclusive breastfeeding and early initiation of breastfeeding $(\mathrm{OR}=5.8)$. The delay in initiation leads to a delay in the development of oxytocin reflexes, which are very important for the contraction of the uterus and the breast milk reflex. Studies show that the earlier breastfeeding begins the earlier and more effective the consolidation of the process, and therefore, a better impact on the after-birth period, which helps in the earlier initiation of the secretion of breast milk(20). This was in line with a study of the prevalence and predictors of 6-month exclusive breastfeeding in a rural area in Egypt, which found that, a highly significant association between exclusive breastfeeding and early initiation of breastfeeding after delivery ${ }^{(18)}$. This study is also not similar to a cross-sectional, health facility-based survey where in Bhaktapur, Nepal about Infant feeding practices $57.0 \%$ of mothers started breastfeeding within the first hour after birth ${ }^{(21)}$. In the current study, among 601 mothers who stopped exclusive BF, $6.2 \%$ were never breastfed infants. $51.8 \%$ stopped at $3 \mathrm{rd}$ month, $31.4 \%$ at 4 th month, and $10.6 \%$ after 5th month. $53.3 \%$ of mothers used herbal in the first 3 days. These results are much lower than Asare et al., who reported that current breastfeeding and continuous breastfeeding at 1 year of age rates of $74.1 \%$ and $76.2 \%$ respectively ${ }^{(17)}$. In the current study, the most comments barriers for exclusive BF and causes of cessation of exclusive BF; $72.4 \%$ of mothers stopped EBF due to family and home responsibilities, $72.4 \%$ felt constrained, $58.9 \%$ said milk is not enough, $58.9 \%$ were convinced that breastfeeding is not sufficient for infants in general, $40.6 \%$ wanted to start weaning, $39.1 \%$ stopped under the pressure of infant's father, $36.4 \%$ wanted to use hormonal contraceptive method for birth spacing, 31.1\% due to doctors opinion, $31.1 \%$ mothers working or studying, $23 \%$ sick mothers or unable to breastfeed, $23 \%$ the belief that the formula is equal to or better than breast milk, $23 \%$ mother's nipple pain or cracks, $8.3 \%$ because mothers taking medications, $4.7 \%$ due to previous negative breastfeeding experience and $4.7 \%$ of mothers stopped EBF due to the desire to diet to lose weight. Similarly, other studies also noted that the principal barrier to the initiation and even continuation of breastfeeding is due to the operative obstetrical intervention (22-23). In the current study, a statistically significant relation was found between exclusive BF and the age of mothers. It is more common in the younger age group $(14.5 \%$ of mothers aged less than 30 y were exclusive breastfeeders compared to $5.6 \%$ among mothers aged more than or equal $30 \mathrm{y}(\mathrm{OR}=2.8))$. These results agreed with Woldie et al.'s study about Factors associated with the duration of exclusive breastfeeding in asthmatic who mentioned that the women least likely to breastfeed are those who are young(24) However, this result was supported by Gijsbers et al. who showed that younger maternal age was associated with a longer duration of breastfeeding(25). Moreover, found a significant association between the prevalence of EBF in mothers aged 2030 years in the current study, $22.4 \%$ of housewives were exclusive breastfeeders compared to $4.6 \%$ among working mothers with a statistically significant difference as exclusive breastfeeding was more in nonworking mothers (OR=5.9) Similarly, Shaheen et al., found housewives (69.8\%) were more likely to breastfeed their infants exclusively(15), and this finding was supported by Setegn et al. who showed that unemployed mothers were about five times more likely to breastfeed exclusively as compared with employed mothers ${ }^{(19)}$. Also, previous studies indicated a signifi- 
cant difference among employed and unemployed mothers about exclusive breastfeeding and also revealed that unemployment of the mothers is a predictor of exclusive breastfeeding $(75.5 \%)^{(13,15,1626)}$. In the current study, mothers with low and middle SES were more practicing exclusive BF representing $24.5 \%, 12.1 \%$ respectively compared to only $2.9 \%$ among high SES ( $O R=11 \& 4.7$ respectively). This finding was consistent with the results of Hossain and Islam, who showed that lower socioeconomic status, favors exclusive breastfeeding; Maternal instinct will always push a mother toward breastfeeding(27). In the current study, there was no significant association was found between exclusive breastfeeding and mother education, father's occupation, and fathers. and this finding agreed with the study by Agampodi et al., (Exclusive breastfeeding in Sri Lanka: problems of interpretation of reported rates) who indicated that additional mother education did not significantly affect the breastfeeding rate ${ }^{(28)}$. In the current study, there was a statistically significant relationship between exclusive $B F$ and frequency of $A N C$ visits $(O R=1.9)$. On the other hand, no statistically, a significant relation was found between EBF and ANC or Place of birth. Although Mothers attending governmental hospitals for ANC more practicing EBF than mothers attending private clinics $(\mathrm{OR}=4.3)$. The findings also showed that those infants who are born in health institutions were about four times more likely to be exclusively breastfed than those who are born at home. Breastfeeding counseling during ANC was also identified as a significant factor associated with EBF practice in some other studies from Egypt ${ }^{(18)}$, Nigeria(30), Debre Markos, Ethiopia(29), and Arbaminch, Ethiopia(31). In the current study, there was a statistically significant relationship between exclusive BF and type of birth, as normal delivery associated with more exclusive BF $21.7 \%$ versus $5.5 \%$ in the $C S$ group $(O R=4.7)$. This could be because mothers may face health complications during/after cesarean section, they may need some longer time to recover from the cesarean section-related pain and discomfort which in turn may present mothers from practicing EBF. It was also suggested that cesarean delivery may result in delayed milk production which may also contribute to a lower rate of EBF practice among cesarean mothers ${ }^{(32}$ 33). In the current study, after logistic regression analysis and adjusting confounding factors; Mother's occupation (Housewife) $(O R=43)$, vaginal delivery $(O R=28.5)$, early initiation of $B F(O R=6.5)$, mothers aged less than 30 y $(O R=2.4)$, and frequency of $A N C$ visits $>4(O R=2.3)$ was independent predictors for exclusive breastfeeding. In agreement with this study, Hossain et al. found antenatal care (ANC) was significantly associated with EBF practice among Bangladeshi mothers from univariate analysis while multivariate analysis showed this factor as insignificant. Mothers who received ANC were 1.33 times more likely to provide EBF to their infants compared to those who did not receive ANC. This could be due to the ANC programs that include breastfeeding counseling which improves the breastfeeding knowledge of mothers and motivates them to exclusively breastfeed their infants ${ }^{(27)}$.

\section{Conclusion}

In conclusion, a small proportion of infants are exclusively breastfed during the first 6 months (10.3\%), despite what is recommended in the national and global infant and young child feeding guidelines. The practice of exclusive breastfeeding among infants less than six months old in the previous $24 \mathrm{~h}$ and complementary feeding 
among infants aged 6-8 months were suboptimal. Exclusive breastfeeding among mothers was influenced by the mother's age and educational status. Interventions emphasizing practical education should therefore be targeted at addressing factors that influence exclusive breastfeeding.

\section{References}

1. Kaar JL, Sauder KA, Shapiro AL, et al. Infant feeding practices in a diverse group of women: The Healthy Start Study. Clin. Med. Insights Pediatr. 2019; 13:1179556518824362.

2. Radzyminski S, \& Callister LC. Mother's beliefs, attitudes, and decision-making related to infant feeding choices. The Journal of $P$, Education. 2016;25(1):18.

3. Feldman WL, Burnham L, Grossman $X$, et al. Weight gain in the first week of life predicts overweight at 2 years: A prospective cohort study. Matern Child Nutr. 2018;14(1): e12472.

4. Dykes F, \& Flacking R. Encouraging breastfeeding: a relational perspective. Early human development. 2010;86(11):733-6.

5. Stanton CK, Dubourg D, De Brouwere $\mathrm{V}$, et al. Reliability of data on cesarean sections in developing countries. Bulletin of WHO. 2005; 83:449-55.

6. Moxon SG, Ruysen $\mathrm{H}$, Kerber KJ, et al. Count every newborn; a measurement improvement roadmap for coverage data. BMC pregnancy and childbirth, 2015, 15.2: 1-23.

7. Nafee Elsayed HM., \& Al-Dossary L. A. Exclusive Breastfeeding, Prevalence and Maternal Concerns: Saudi and Egyptian Mothers. JEP. 2016;7(3):511.

8. Fjeld E, Siziya S, Katepa-Bwalya M, et al. 'No sister, the breast alone is not enough for my baby's qualitative assessment of potentials and barriers in the promotion of exclusive breastfeeding in southern Zambia. Int. Breastfeed. J. 2008;3(1):26.

9. World Health Organization. "Babyfriendly hospital initiative: revised, updated and expanded for integrated care. 2009.

10. EL-Gilany A.; EL-Wehady A.; EL-Wasify $M$. Updating and validation of the socioeconomic status scale for health research in Egypt. (EMHJ), 2012, 18.9.

11. Tiruye G, Mesfin F, Geda B, et al. Breastfeeding technique, and associated factors among breastfeeding mothers in Harar city, Eastern Ethiopia. Int Breastfeed J. 2018,13.

12. Victora CG, Bahl R, Barros AJ, et al. Breastfeeding in the 21st century: epidemiology, mechanisms, and lifelong effect. The Lancet. 2016;387 10017):475-90.

13. Tan KL. Factors associated with exclusive breastfeeding among infants under six months of age in peninsular Malaysia. Int. Breastfeed. J. 2011;6(1):2.

14. UNICEF. Improving breastfeeding, complementary foods, and feeding practices. 2018..

15. Shaheen H, Hegazy N, Sakr S. The barriers to breastfeeding among women: a single-center experience. MMJ 2018;31(3):855-61.

16. El-Zanaty, F., \& Wany, A. Macro International. Egypt Demographic and Health Survey 2008, Cairo, Egypt: Ministry of Health, Int Fam Plan Perspect, 2014, 29: 158-66.

17. Asare BY-A, Preko JV, Baafi D, et al. Breastfeeding practices, and determinants of exclusive breastfeeding in a cross-sectional study at a child welfare clinic in Tema Manhean, Ghana. Int Breastfeed J. 2018;13(1):12.

18. Ghwass MMA, \& Ahmed D. Prevalence and predictors of 6-month exclusive breastfeeding in a rural area in Egypt. Breastfeed Med. 2011;6 (4):191-6. 
19. Setegn T, Belachew T, Gerbaba M, et al. Factors associated with exclusive breastfeeding practices among mothers in Goba district, southeast Ethiopia: a cross-sectional study. Int Breastfeed J. 2012;7(1):17.

20. Haroun HM, Mahfouz MS, Ibrahim BY. Breastfeeding indicators in Sudan: a case study of Wad Medani town. Sudanese J Public Health. 2008;3(2):81-90.

21. Ulak $M$, Chandyo RK, Mellander L, et al. Infant feeding practices in Bhaktapur, Nepal: a cross-sectional, health facility-based survey. Int Breastfeed J. 2012;7(1):1.

22. Chien LY, \& Tai CJ. Effect of delivery method and timing of breastfeeding initiation on breastfeeding outcomes in Taiwan. Birth. 2007;34(2):123-30.

23. Saeed G, Fakhar S, Imran T, et al. The effect of modes of delivery on infants' feeding practices. Iran. J. Med. Sci. 2011;36(2):128.

24. Woldie TG, Kassa AW, Edris M. Assessment of exclusive breastfeeding practice and associated factors in Mecha District, Northwest Ethiopia. Sci J Public Health. 2014;2(4):330-6.

25. Gijsbers B, Mesters I, Knottnerus JA, et al. Factors associated with the duration of exclusive breastfeeding in asthmatic families. Health Educ. Res. 2008;23(1):158-69.

26. Taveras EM, Capra AM, Braveman PA, et al. Clinician support and psychosocial risk factors associated with breastfeeding discontinuation. Pediatrics. 2003;112(1):108-15.

27. Hossain M, Islam A, Kamarul $T$, et al. Exclusive breastfeeding practice during first six months of an infant's life in Bangladesh: a country-based cross-sectional study. BMC Pediatr. 2018;18(1):93.

28. Agampodi SB, Agampodi TC, De Silva A. Exclusive breastfeeding in Sri Lanka: problems of interpretation of reported rates. Int Breastfeed J. 2009;4(1):14.
29. Mekuria G, \& Edris M. Exclusive breastfeeding, and associated factors among mothers in Debre Markos, Northwest Ethiopia: a cross-sectional study. Int Breastfeed J. 2015;10(1):1.

30. Agho KE, Dibley MJ, Odiase Jl, et al. Determinants of exclusive breastfeeding in Nigeria. BMC pregnancy and childbirth. 2011;11(1):2.

31. Echamo M. Exclusive breastfeeding in Arbaminch, SNNPR, Ethiopia. Harar Bull Health Sci. 2012; 5:44-59.

32. Dewey KG, Nommsen-Rivers LA, Heinig MJ, et al. Risk factors for suboptimal infant breastfeeding behavior, delayed onset of lactation, and excess neonatal weight loss. Pediatrics. 2003;112(3):607-19.

33. Grajeda Rn, \& Pérez-Escamilla R. Stress during labor and delivery is associated with delayed onset of lactation among urban Guatemalan women. J. Nutr. 2002;132(10):305560. 